\title{
Hospital beds and how to survive them
}

\author{
Robert J Maxwell
}

In late 1994, after major knee surgery for osteoarthritis, I found myself confined to a hospital bed for about three weeks. For much of that time I could not get out of the bed and initially any substantial movement was quite difficult and painful.

What struck me forcibly was that the bed-large, solid, built to last - was not at all user friendly from my point of view. Although it could be raised and lowered (and no doubt tilted) this involved energetic actions by somebody other than me. Even the back rest, which determined whether I could lie down or sit up and at what angle, was a heavy contraption which I could only adjust for myself if I was able to get out of its way, roll on to my front, and fight with it. Otherwise I had to call a nurse to do it for me, and I always hesitated, believing that the nurses had more important things to do.

The Körner Committee, which considered many definitions instrumental to National Health Service (NHS) information systems, reported a definition of a bed in 1982 (box), and I have to say that that ponderous definition is exactly what my hospital bed felt like.

My bed was a King's Fund bed, designed to the specification developed by a King's Fund Working Party in 1966. So it was (in a vicarious sense) my personal responsibility as chief executive of the King's Fund. This was the first bed in widespread use in the United Kingdom with wheels, height adjustment, head and foot elevation, space to store bedclothes during bed making, explicit consideration of cleaning and sterilisation, safety from static electricity build up and discharge in the presence of explosive anaesthetic gases, and facilities to use equipment around the bed. It was in its time revolu-

The King's Fund, founded by Edward VII when Prince of Wales, helps to support the hospitals of London, by making grants, reviewing policy, developing health equipment, etc.

The King's Fund, 11-13 Cavendish Square, London W1M OAN Robert J Maxwell, chief executive of the King's Fund

Accepted for publication 18 August 1997

\section{The Körner Committee definition of a bed}

A device or arrangement that may be used to permit a patient to lie down when the need to do so is a consequence of the patient's condition rather than a need for active intervention-such as examination, diagnostic investigation, manipulative treatment, obstetric delivery, or transport.

users and carers (defined to include clinicians and also people who clean, move, or maintain beds). "Users" comprised adults and children with a range of medical conditions and disabilities. "Clinicians" included not only doctors and hospital nurses but also physiotherapists, occupational therapists, community nurses, and radiographers. Others consulted included manufacturers and people who provide information to help in choosing beds for health care. Five points stand out.

(1) Hospital beds are not the prime currency. For most patients, a hospital stay is relatively short and they do not expect to enjoy it. If their bed at home needs modification for their condition, that is far more important than the hospital bed that caused me such frustration. In the 1970s, the King's Fund bed spread from acute to long stay wards, and much improved them. In the 1990 s, elderly people who are ill mostly live in nursing or residential homes, or in the community, in beds that are often worse than the hospital beds that preceded the original King's Fund specification.

(2) For many people, as for me, personal control over their own bed is of great importance. Typically beds do not seem to be designed with this in mind. An especially vivid and worrying comment in our consultation from a patient with multiple sclerosis was, "I lay down and I'm in that position all night. I can't move ... so of course within two hours I'm in a lot of pain because you can't stay rigid all the time can you? (my occupational therapist) she fixed me something ... under the bed that lifts the back up, oh and within half an hour the backache's gone, brilliant". Many people report the boost to autonomy that electrical controls can bring. No doubt, however, they are substantially more expensive and the NHS and social services would generally view them as an unwarranted (or unaffordable) extravagance.
Recently, to celebrate the King's Fund centenary, we have begun to re-examine the bed, with the help of focus groups representing 
In the long run they are not necessarily right about this.

As an arthritic patient put it to us, "I would like to have the bed that I had in a private hospital. You just pressed something and you went up ... but you can't have that." Electrical controls apart, other aids can also help-for example, for those who have strong arms the so called monkey pole, which allows you to change position by pulling yourself up and swinging laterally. The crucial point is-if humanly possible - to be able to change position on your own initiative, to be able to reach things (book, glasses, etc), and to summon help.

(3) Avoiding pressure sores is vital. So also is minimising physical discomfort. For anybody who cannot readily change positionespecially for older people because of their fragile skin-pressure sores are a hazard, and one that can cause prolonged misery. Granted good nursing care they ought to be avoidable: indeed their incidence is one measure of quality failure. In Florence Nightingale's words "The first requirement in a hospital is that it should do the sick no harm." Unfortunately we do not always meet that requirement, either in avoiding hospital acquired infections or in avoiding pressure sores.

There have been big advances in equipment-mattresses particularly - that help in this regard, both in the hospital and at home. Fabrics also contribute, especially when there is a problem of incontinence; many people find the traditional rubber sheet hot and uncomfortable, but today there are better options than this.

(4) Although the patients' needs come first, the needs of nurses and other carers are also of great importance. The typical King's Fund bed is heavy and cumbersome, but at least it can be lowered and raised to ease the work of the carers. This is seldom the case for beds at home. Lifting is a hazardous process, in which nurses and carers are at constant risk of injury, particularly injuries to the back, from which the harm can be permanent. Not only do beds need to be designed to reduce the risk of injury, but also everyone concerned should be alert to the dangers, and trained to minimise them. We owe it to informal carers (often themselves elderly) to train them to take care of themselves while caring for others. Not only do we owe them that morally: it is also in our collective interest, as they are a crucial resource in limiting the burdens that fall on the State.

(5) There is a strong case for an information centre and service on beds and related matters where families and carers can come not only for advice, but to try things out. As our informants put it, "It's such a hit and miss affair. If you go out and buy a mattress, for a short while-if you've got any sense-you do lie on it, but you're doing it for five or 10 minutes at most. It leaves you completely clueless really as to what it's going to be like for a whole night." Somebody else added that you "should be able to get it on a sale or return."

Although disabled living centres provide some of this, they are not widely known. Too often families either "stick with" the beds, mattresses, and bedding that they already have, or they buy with inadequate information on which to make good choices. It is in the interests of us all to change this situation. The information centre-or centres-would not only help users and their families-which is vital-it would also feed back to manufacturers and regulators information about what users and carers want. It would monitor and research as well as inform. With new technology in information and design it should be able to move from "off the peg" to "tailor made" solutions, based on a sophisticated examination of options, individual needs, and preferences.

The original King's Fund bed broke new ground in product specification and design. It did so mainly from the viewpoint of the providers of acute hospital services, and at a time when technology was much less advanced than now. By contrast, what seems to be needed currently is a method of enabling users, service providers, and equipment suppliers to work together much more effectively. Among them, they should be able to find out what is needed, develop and evaluate solutions, and choose the best combination of effectiveness and cost, both in general and in individual cases.

As well as making better products (which the King's Fund achieved by its work in the mid-1960s) we should ensure that the market for beds works better, putting personal independence more firmly in the picture. The NHS must put value ahead of minimum cost. Users and their families must be willing to invest more time, effort, assertiveness, and money into choosing. For those who are bedbound or chairbound, few things are more important than the comfort of their bed or chair. Collectively we will only get the beds that we deserve.

I have great pleasure in acknowledging the help and advice of my colleagues at the King's Fund, particularly John Mitchell and John McClenahan, and of everyone who is contributing to the King's Fund bed project which they lead. Anyone who wants to give additional advice to the project should contact John McClenahan, Secretary of the King's Fund bed project. Tel: 00441713072616 . 